\title{
Kartogenin Inhibits Prostate Cancer Cell Growth Through Smad2 Activation and Decreases Androgen Receptor Nuclear Localization
}

\author{
MANABU TAKAI ${ }^{1}$, KYOJIRO KAWAKAMI $^{2}$, YASUNORI FUJITA ${ }^{3}$, TAKU KATO ${ }^{4}$, DAIKI KATO ${ }^{1}$, \\ KOJI IINUMA ${ }^{1}$, TAKUYA KOIE ${ }^{1}$, MASAFUMI ITO ${ }^{3}$ and KOSUKE MIZUTANI ${ }^{1,5}$ \\ ${ }^{1}$ Department of Urology, Gifu University Graduate School of Medicine, Gifu, Japan; \\ ${ }^{2}$ Research Team for Mechanism of Aging, Tokyo Metropolitan Institute of Gerontology, Tokyo, Japan; \\ ${ }^{3}$ Research Team for Functional Biogerontology, Tokyo Metropolitan Institute of Gerontology, Tokyo, Japan; \\ ${ }^{4}$ Department of Urology, Asahi University Hospital, Gifu, Japan; \\ ${ }^{5}$ Department of Urology, Kizawa Memorial Hospital, Gifu, Japan
}

\begin{abstract}
Background/Aim: De-differentiation is a key step for the progression of cancer cells. This study investigated the anti-tumor effect of kartogenin (KGN), which has the ability to differentiate cells, on prostate cancer $(P C)$ cells. Materials and Methods: The effects of KGN on androgen receptor (AR) nuclear localization, prostate-specific antigen (PSA) expression, and Smad2 activation as well as the growth of $P C$ cell lines (LNCaP, 22Rv1 and PC-3) were analyzed. Results: $K G N$ significantly inhibited growth of AR-expressing LNCaP and 22Rv1 cells but not of AR-lacking PC-3 cells. KGN decreased AR nuclear localization and PSA expression, but did not enhance the anti-tumor effect of bicalutamide in $L N C a P$ cells. KGN activated Smad 2 both in the absence and presence of TGF- $\beta 1$. KGN also inhibited growth of docetaxelresistant PC cells, 22RvIDR, and re-sensitized them to the agent. Conclusion: KGN has a potential as a novel therapeutic for PC patients after treatment failure.
\end{abstract}

Recent advances in prostate cancer (PC) research have provided several new treatment options for advanced and castration-resistant prostate cancer (CRPC). Among them, targeting the androgen receptor (AR) signaling axis is an important strategy and the second-generation androgen

This article is freely accessible online.

Correspondence to: Kosuke Mizutani, MD, Ph.D., 1-1 Yanagido, Gifu, Gifu 501-1194, Japan. Tel: +81 582306338, Fax: +81 582306341,e-mail: mizutech@gifu-u.ac.jp; Masafumi Ito, MD, PhD, 35-2 Sakae-cho, Itabashi-ku, Tokyo 173-0015, Japan. Tel: +81 339643241, Fax: +81 335794776, e-mail: mito@tmig.or.jp

Key Words: Prostate cancer, kartogenin, Smad2, androgen receptor. receptor inhibitors (SG-ARIs) have been recently approved (1-3). Although SG-ARIs show improved outcomes in patients with advanced hormone-sensitive prostate cancer (HSPC) and CRPC, eventually, resistance to SG-ARIs develops via several mechanisms. AR signaling axis is still one of the major targets for SG-ARI-refractory PCs (4).

Apart from AR signaling, AR-independent mechanisms of resistance to SG-ARIs, including TGF- $\beta$ signaling pathway, have also been reported (4). TGF- $\beta$ has been observed to inhibit the growth of normal cells, and to promote progression and metastasis of cancer cells via enhancing epithelial-mesenchymal transition (EMT), suggesting that TGF- $\beta$ signaling pathway could be a novel therapeutic target for cancer (5-7).

Kartogenin (KGN), a small heterocyclic compound, stimulates differentiation of human mesenchymal stem cells (MSCs) to chondrocytes, therefore KGN has been considered to be a candidate drug for tissue repairing or regeneration (811). Cai et al. showed that KGN regulates TGF- $\beta / S$ mad pathway via increasing phosphorylation of the Smad family proteins and proposed its potential role in chondrogenesis (10). Since Smad proteins are main regulators of TGF- $\beta$ signaling, it would be theoretically possible for KGN to inhibit growth of cancer cells by inducing their differentiation (12). To date, no report has been published on the role of KGN in cancer cell growth. In the present study, we investigated the role of KGN on PC cell growth and its underlying mechanisms.

\section{Materials and Methods}

Cell lines. Human PC cell lines LNCaP and PC-3 were obtained from the JCRB Cell Bank (Osaka, Japan), and 22Rv1 was purchased from the European Collection of Authenticated Cell Cultures. Cells were maintained in RPMI-1640 (Wako Pure Chemical Industries, 
Osaka Japan) containing penicillin, streptomycin and $10 \%$ fetal bovine serum (Equitech-Bio, Kerrville, TX, USA).

Reagents. Kartogenin, bicalutamide and docetaxel purchased from Selleck Chemicals (Houston, TX, USA) were dissolved in dimethyl sulfoxide (DMSO). TGF- $\beta 1$, purchased from PeproTech (Cranbury, NJ, USA), was reconstituted at $0.1 \mathrm{mg} / \mathrm{ml}$ in $10 \mathrm{mM}$ citric acid, $\mathrm{pH}$ 3.0 containing $0.1 \%$ BSA in accordance with the manufacturer's instructions.

Cell viability assay. Cells (LNCaP and 22Rv1: $3.0 \times 10^{3}$, PC-3: $1.0 \times 10^{3}$ ) were seeded into 96 -well plates and cultured in complete medium. Twenty-four hours after seeding, cells were treated with KGN, TGF- $\beta 1$, bicalutamide and/or docetaxel. WST- 1 assay was performed $72 \mathrm{~h}$ after treatment using WST-1 assay kit (Roche Diagnostics, Mannheim, Germany).

Cell treatments and western blot analysis. Western blot analysis was performed as described in previous reports $(13,14)$. Briefly, cells $\left(4.0 \times 10^{5}\right)$ were seeded onto 6-well plates and cultured in complete medium containing FBS. Twenty-four hours later, medium was changed to serum-free medium with or without KGN. In specified experiments, cells were also treated with TGF- $\beta 1$. Whole cell lysates were harvested and suspended in RIPA (radioimmunoprecipitation) buffer containing protease inhibitor cocktail and phosphatase inhibitor cocktail (Sigma Aldrich, St. Louis, MO, USA). The cell lysates were subjected to SDS-PAGE followed by Western blotting. All primary antibodies were purchased from Cell Signaling Technology (Danvers, MA, USA). The immunoreactive proteins were detected using horseradish peroxidase-conjugated anti-rabbit antibody (Cell Signaling Technology) and ImmunoStar (FUJIFILM Wako Pure Chemical, Osaka, Japan).

Cell treatment and extraction of nuclear and cytoplasmic proteins. Cells $\left(5.0 \times 10^{5}\right)$ were seeded in 6 -well plates and medium was changed to serum free medium $24 \mathrm{~h}$ after seeding. After treatment with $\mathrm{KGN}$ for $24 \mathrm{~h}$, nuclear and cytoplasmic proteins were separated using NE-PER Nuclear and Cytoplasmic Extraction Reagents (Thermo Scientific, Waltham, MA, USA). Extracted proteins were subjected to western blotting.

Statistical analysis. Statistical analysis was performed by Student's t-test and one-way ANOVA followed by Turkey's multiple comparison test using Graph Pad Prism 7 version 7.03 (Graph Pad Software, San Diego, CA, USA). Differences were considered significant when $p<0.05$.

\section{Results}

$K G N$ inhibited growth of $22 R v 1$ and LNCaP cells. In order to investigate the anti-tumor effect of KGN in PC cells, cell proliferation assay was performed. Treatment with KGN significantly inhibited growth of LNCaP and 22Rv1 cells but not of PC-3 cells (Figure 1A). LNCaP, 22Rv1 and PC-3 cells were used as models of HSPC with AR expression, CRPC with AR expression and CRPC without AR expression, respectively (Figure 1B). We also examined the anti-tumor effect of $\mathrm{KGN}$ in the absence or presence of bicalutamide, an AR inhibitor, in LNCaP and 22Rv1 cells.
The effect of the combination of KGN and bicalutamide was not significantly different compared to that of bicalutamide alone (Figure 1C and D).

KGN inhibited nuclear localization of AR. KGN inhibited growth of AR-expressing PC cells regardless of the sensitivity to castration, which led us to hypothesize that KGN might be involved in the AR signaling pathway. AR is translocated to the nucleus following stimulation with androgens (testosterone and dihydrotestosterone), resulting in increased transcription of AR-regulated genes. Here, we investigated whether $\mathrm{KGN}$ inhibits nuclear localization of AR in AR-expressing LNCaP cells. The results showed that KGN significantly inhibited AR nuclear localization in $\mathrm{LNCaP}$ cells that were cultured in serum-free medium (Figure 2A). We also investigated expression of PSA, one of the AR target genes. As expected, PSA expression was decreased by KGN treatment (Figure 2B).

KGN induced phosphorylation of Smad2. Since KGN was reported to be involved in the activation of Smad signaling, we examined whether Smad proteins were activated by KGN. As shown in Figure 3, phosphorylation of Smad2 was significantly increased by KGN treatment in LNCaP cells cultured in serumfree medium. The activation was transient and did not last beyond $30 \mathrm{~min}$. Although $\mathrm{Smad} 3$ was reported to be involved in AR transactivation, Smad3 was not detectable (data not shown). Akt, which is well known to be important for cell growth, was not activated by KGN (Figure 3A).

TGF- $\beta 1$-induced Smad2 phosphorylation was enhanced by KGN pretreatment. Smad proteins are key molecules of TGF$\beta$-induced intracellular signaling response. To confirm the role of $\mathrm{KGN}$ in Smad2 activation, we investigated whether pretreatment with KGN affects TGF- $\beta 1$-induced Smad2 phosphorylation in LNCaP cells cultured in serum-free condition. Twenty-four-hour pretreatment with KGN tended to increase TGF- $\beta 1$-induced phosphorylation of Smad2, although not statistically significantly, suggesting that KGN pretreatment enhanced the reactivity of Smad 2 to TGF- $\beta 1$ (Figure 4A and B). We also studied the anti-tumor effects of TGF- $\beta 1$ alone and in combination with KGN. TGF- $\beta 1$ showed no effect on the growth of LNCaP cells both in the absence and presence of KGN (Figure 4C). These results suggested that Smad2 activation induced by KGN may be stronger than that induced by $100 \mathrm{ng} / \mathrm{ml}$ of TGF- $\beta 1$ and thus the anti-tumor effect was detectable only when cells were treated with $\mathrm{KGN}$.

$K G N$ inhibited growth of the docetaxel-resistant PC cell line $22 R v 1 D R$. Advanced PC is treated with chemotherapeutic agents, such as docetaxel (DTX). Lastly, we investigated the anti-tumor effect of $\mathrm{KGN}$ in the docetaxel-resistant PC cell 
A

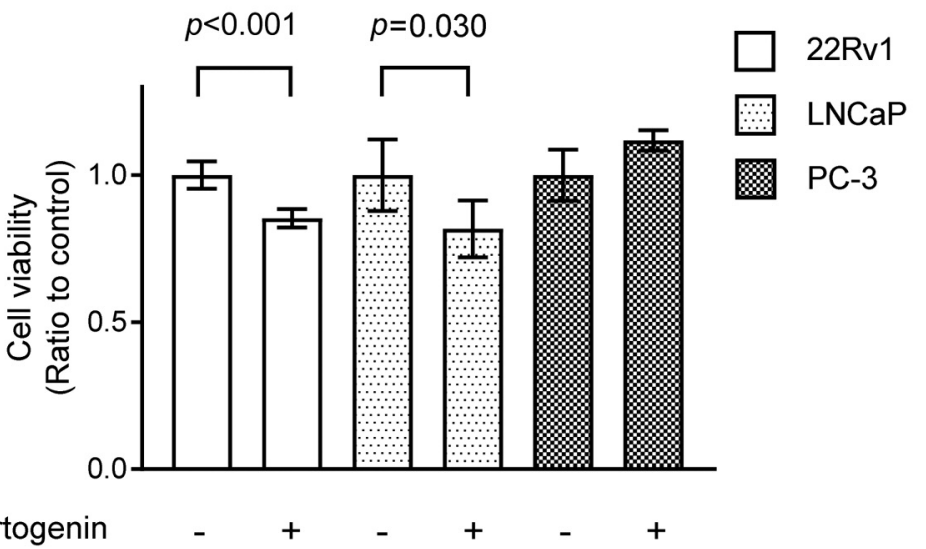

Kartogenin $\quad-\quad+\quad-\quad+\quad-\quad+$
B

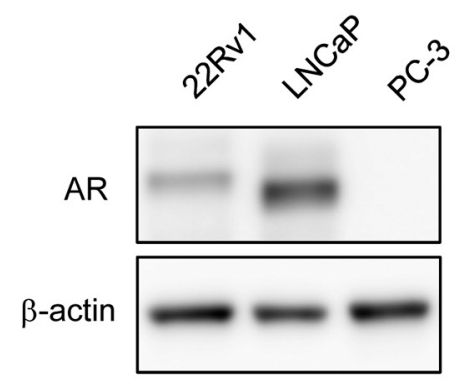

C
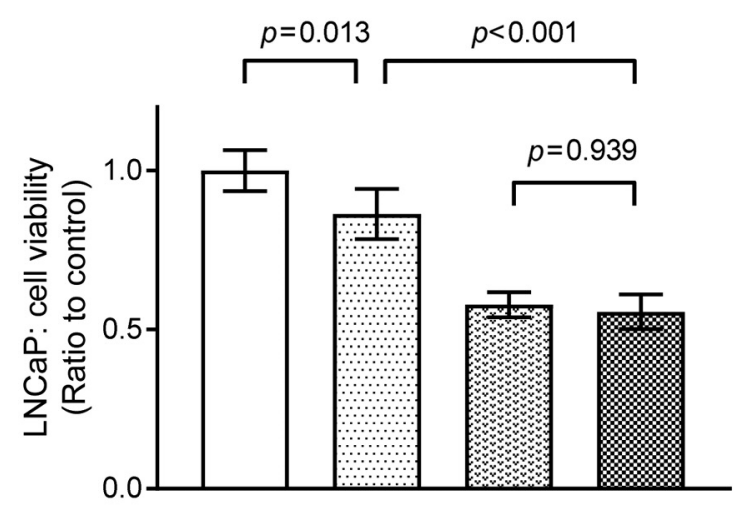

Kartogenin

Bicalutamide

Figure 1. Kartogenin (KGN) inhibited prostate cancer (PC) cell growth. A: Anti-tumor effect of KGN in PC cell lines. Cells (22Rv1 and LNCaP; $\left.3 \times 10^{3}, P C-3 ; 1 \times 10^{3}\right)$ were plated in 96-well plates. Twenty-four hours after seeding, $100 \mu M$ of KGN or vehicle (DMSO) were added. Cell viability was measured $72 \mathrm{~h}$ after treatment by the WST-1 assay. Statistical analysis was performed using Student's $t$-test ( $n=5)$. B: AR expression in PC cell lines. AR expression in each PC cell line was evaluated by western blotting. Expression of $\beta$-actin was used as a loading control. $C$ and D: Effect of the combination of KGN and bicalutamide. LNCaP and $22 R v 1$ cells $\left(3 \times 10^{3}\right)$ were plated in 96-well plates. Twenty-four hours after seeding, KGN $(100 \mu \mathrm{M})$, bicalutamide $(10 \mu \mathrm{M})$ or both was added and cell viability was measured $72 \mathrm{~h}$ after treatment by the WST-1 assay (left panel; LNCaP, right panel; 22Rv1). Statistical analysis was performed using one-way ANOVA followed by Turkey's multiple comparison test ( $n=5)$.

line 22Rv1DR, which was established previously in our laboratory (14). As shown in Figure 5, DTX significantly inhibited growth of 22Rv1 cells but not that of 22Rv1DR cells. KGN significantly inhibited growth of 22Rv1DR cells and the combination of KGN and DTX significantly inhibited growth of 22Rv1DR cells compared to KGN or DTX alone.

\section{Discussion}

In this study, we demonstrated for the first time the antitumor effect of KGN in PC. SG-ARIs are now widely used for either advanced HSPC or CRPC, but most PC treated with these agents eventually acquire resistance (4). The
PARP inhibitors olaparib and rucaparib were approved for the treatment of patients with metastatic CRPC prior to treatment with SG-ARIs and/or taxane-based chemotherapy, however, imaging-based progression-free survival by SG-ARIs at 12 months was up to approximately $30 \%(15,16)$. Therefore, it is an urgent need to discover novel therapeutic agents based on different approaches. Although earlier studies on several cancers suggested that the TGF- $\beta /$ Smads pathway could be a possible therapeutic target, approved agents targeting this pathway are not available yet (7). In the current study, we investigated the anti-tumor effect of KGN that was reported to stimulate Smad signaling in PC cells. We demonstrated that $100 \mu \mathrm{M}$ 
A

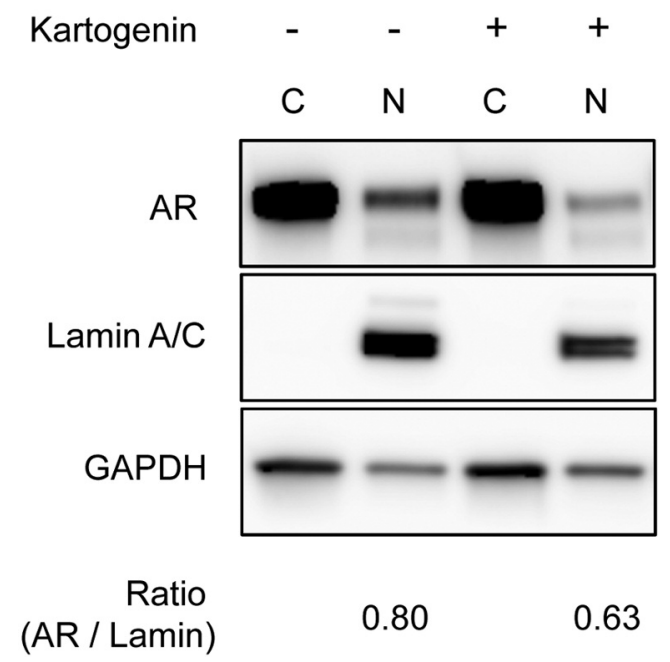

B

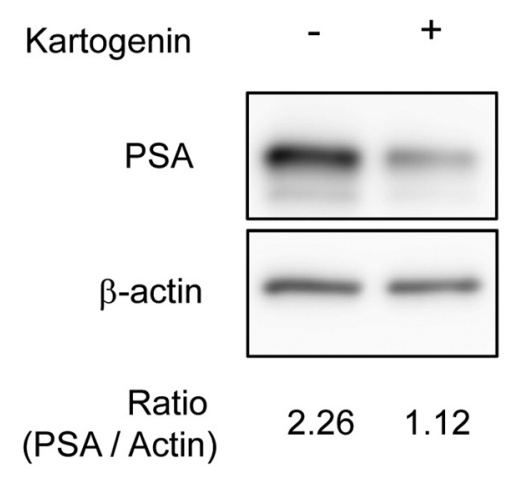

Figure 2. Kartogenin (KGN) decreased androgen receptor (AR) nuclear localization and prostate specific antigen (PSA) expression. A: Nuclear localization of AR in LNCaP cells. Nuclear and cytoplasmic proteins were separated from LNCaP cells that were cultured in serum-free medium with or without KGN. Lamin A/C and GAPDH were used as nuclear and cytoplasmic markers, respectively. Data are representative of two independent experiments. B: Expression of PSA in LNCaP cells. PSA expression was decreased $24 \mathrm{~h}$ after treatment with KGN (100 $\mu M)$ in serumfree medium. $\beta$-actin was used as a loading control. Data are representative of two independent experiments.

A

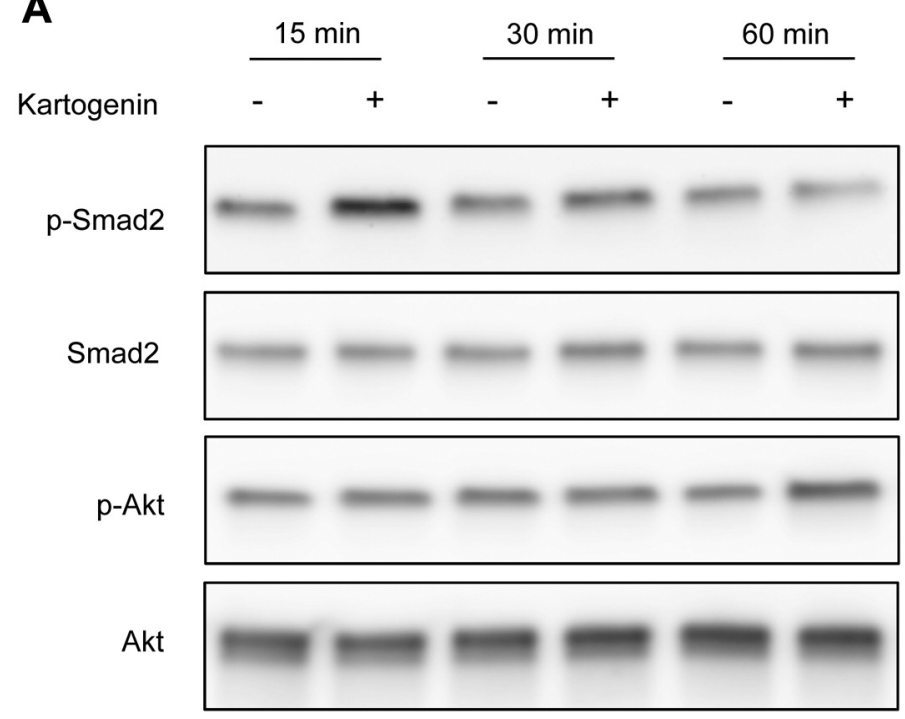

B

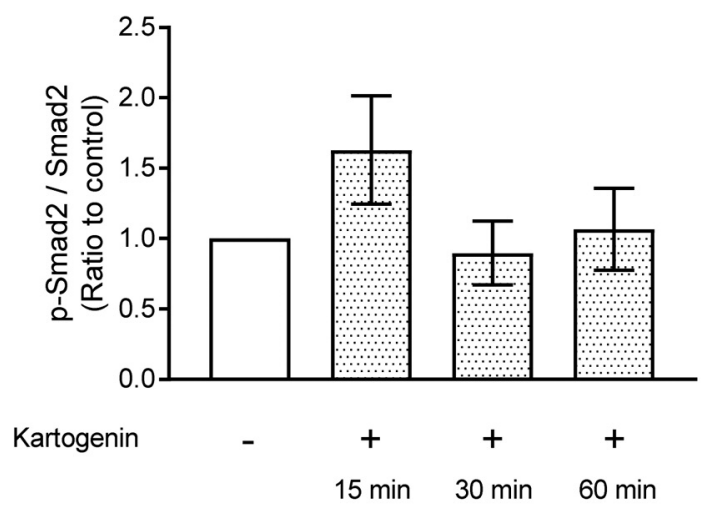

Figure 3. Kartogenin (KGN) increased Smad2 phosphorylation. A: Phosphorylation of Smad2 and Akt was evaluated 15, 30 and 60 mins after treatment with $K G N(100 \mu M)$ in LNCaP cells that had been serum-starved overnight prior to treatment. Data are representative of three independent experiments. B: Signal intensity was measured by ImageJ software and the ratio of phosphorylated Smad2 to Smad2 were calculated. Mean and SD are shown ( $n=3$ ).

KGN inhibited growth of $\mathrm{LNCaP}$ and 22Rv1 cells. There is a report showing that $100 \mu \mathrm{M}$ of KGN does not have any toxicity in human mesenchymal stem cells, chondrocytes, osteoblasts, and synoviocytes. (8). Indeed, $0.1 \mu \mathrm{M}$ to 10 $\mu \mathrm{M}$ of KGN had neither toxic nor anti-tumor effect (data not shown), hence we used KGN at $100 \mu \mathrm{M}$ in the subsequent experiments, as well as in the cell viability assay. 
A

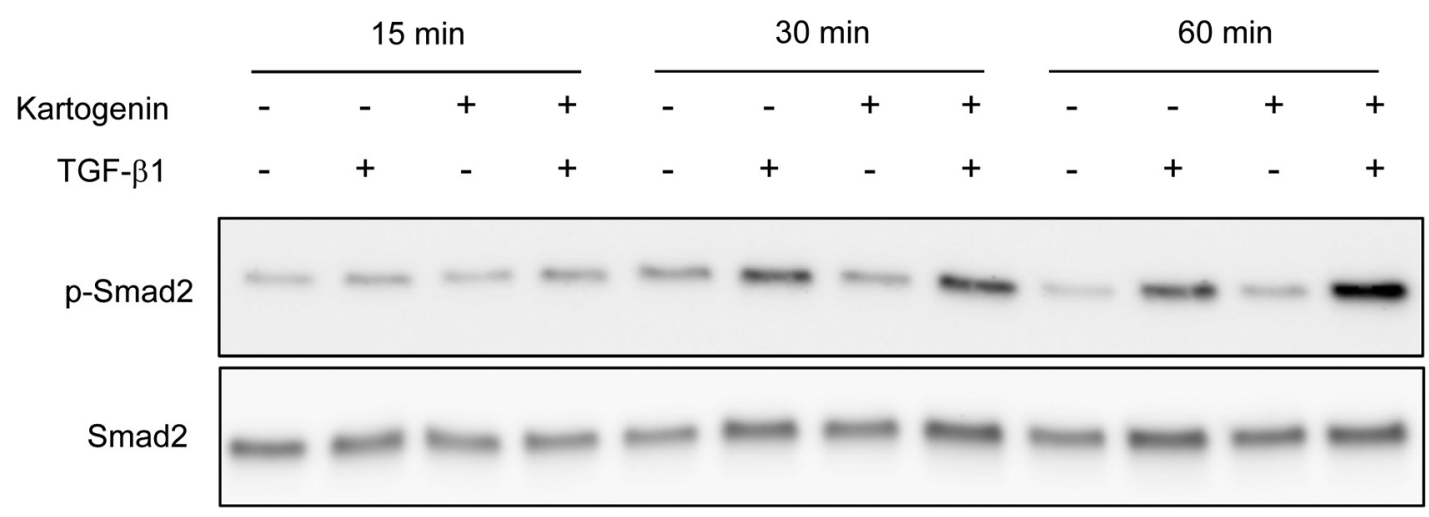

B

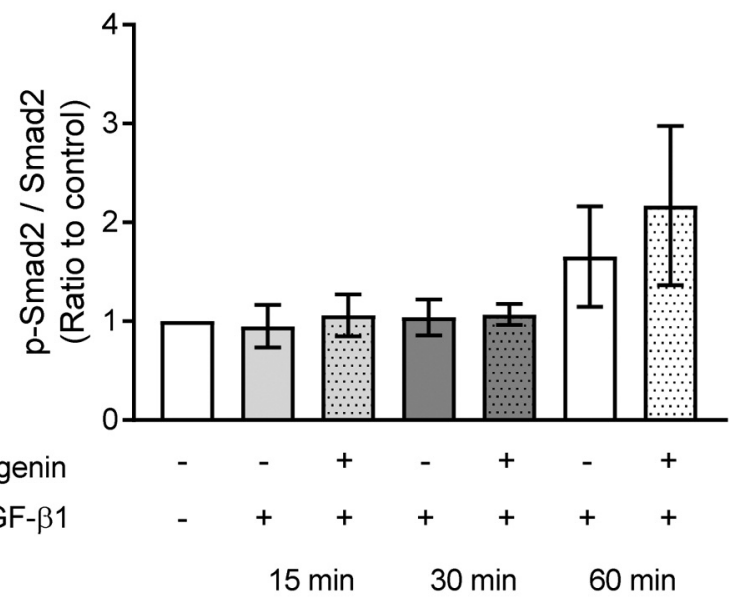

C

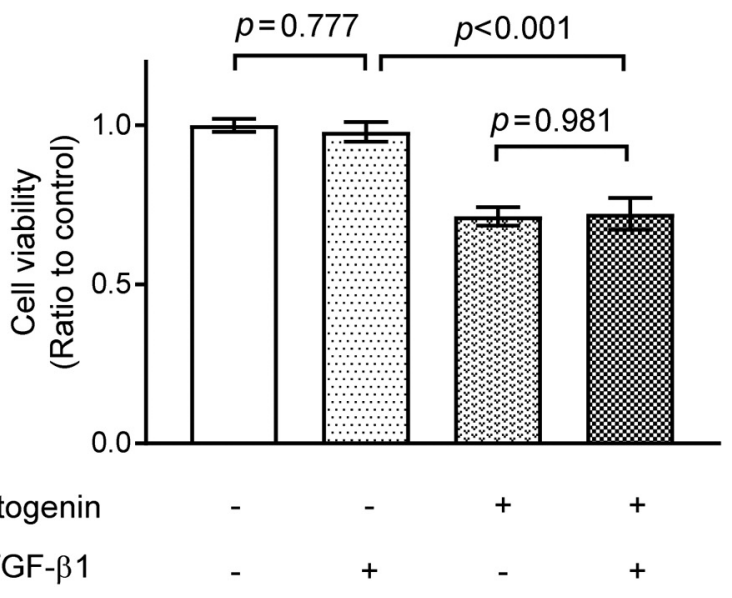

Figure 4. Pretreatment of kartogenin (KGN) enhanced TGF- $\beta 1$-induced Smad2 phosphorylation. A: Phosphorylation of Smad2 by TGF- $\beta 1$ (100 $n g / m l)$ was evaluated in 24-h serum-starved LNCaP cells that were treated with or without $100 \mu M$ KGN. Data are representative of three independent experiments. B: Signal intensity was measured by ImageJ software and the ratio of phosphorylated Smad2 to total Smad2 was calculated. Mean and SD are shown ( $n=3)$. C: Effect of the combination of KGN and TGF- $\beta 1$ on cell viability. LNCaP cell $\left(3 \times 10^{3}\right)$ were plated in 96-well plates. Twenty-four hours after seeding, TGF- $\beta 1$ (100 ng/ml), KGN (100 $\mu \mathrm{M})$ or both was added, and cell viability was measured $72 \mathrm{~h}$ after treatment by WST-1 assay. Statistical analysis was performed using one-way ANOVA followed by Turkey's multiple comparison test (n=5).

AR signaling is an essential target even in SG-ARIsresistant PC. The SG-AGIs enzalutamide, apalutamide and darolutamide are potent AR antagonists, thereby inhibit AR nuclear translocation. Since these agents bind to AR with high affinity and block its interaction with androgens, novel therapeutic targets in PC with resistance to these agents may be located downstream of AR. Our data demonstrated that the effect of the combination of KGN and bicalutamide on cell growth was not significantly different than that of bicalutamide alone, implying that $\mathrm{KGN}$ has weak or no AR antagonistic activity. On the other hand, KGN decreased AR nuclear localization and decreased PSA expression, suggesting that KGN may somehow affect AR signaling pathway.
A previous study demonstrated that TGF- $\beta 1$-mediated Smad 2 activation induced EMT in PC. It was also reported that phosphorylated Smad2 was increased in CRPC compared to HSPC (17). Furthermore, clinical trials to examine the effect of inhibiting the TGF- $\beta$ pathway are now on-going for several types of cancer (7). On the other hand, it has been shown that TGF- $\beta 1$ did not show any effect on the proliferation of $\mathrm{LNCaP}$ cells but inhibited growth of PC-3 and DU-145 cells $(18,19)$. It has been well documented that TGF- $\beta$ has differential biological effects in different cells and in different phases of malignancy $(6,20)$. The dual roles of TGF- $\beta$, which initially suppresses and then promotes cancer progression, may explain our different results between LNCaP/22Rv1 and PC-3 cells. Further research is needed to clarify the controversial results. 


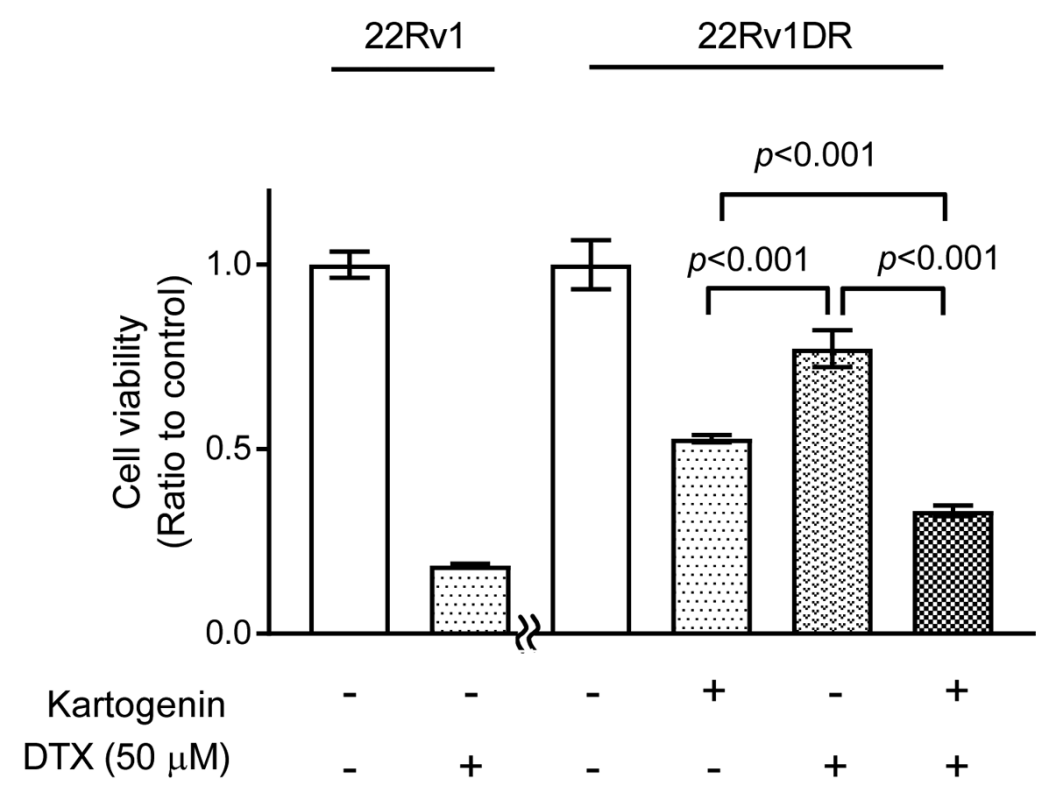

Figure 5. Kartogenin $(K G N)$ inhibited growth of $22 R v 1 D R$ cells. $22 R v 1$ and $22 R v 1 D R$ cells $\left(3 \times 10^{3}\right)$ were plated in 96-well plates. Twenty-four hours after seeding, cells were treated with DTX $(50 \mathrm{nM})$ alone or in combination with KGN $(100 \mu \mathrm{M})$. Cell viability was determined 120 h after treatment. Statistical analysis was performed using one-way ANOVA followed by Turkey's multiple comparison test $(n=5)$.

Elevated phosphorylation of Smad2/3 by KGN was shown in cartilage stem/progenitor cells (11). We demonstrated that phosphorylation of Smad2 by KGN was increased in LNCaP cells, which is consistent with previous studies. In addition, the combination of TGF- $\beta 1$ and KGN led to enhanced phosphorylation of Smad2, suggesting that KGN may contributes to Smad2 activation. Chipuk et al. reported that AR directly associates with and activates Smad3 but not Smad2 (21). Although Smad3 has been demonstrated to be involved in AR signaling in $\mathrm{PC}$, there has been no report showing a direct interaction of Smad2 with AR. Nevertheless, we showed a possible role for $\mathrm{KGN}$ in inhibiting AR signaling pathway, which was accompanied by Smad2 activation. The precise mechanisms underlying the interaction between Smad2 and AR signaling and of the ant-tumor effect mediated by KGN needed to be elucidated. KGN is also efficacious on docetaxel-resistant PC cells as well as parental cells. Notably, the combination of KGN with DTX significantly reduced DTX-resistance in DOC-resistant CRPC cells that recapitulate clinical features of highly advanced PC patients with treatment failure.

In conclusion, KGN inhibited growth of CRPC and chemo-resistant CRPC cells through AR nuclear localization reduction and Smad2 activation. Our results suggest that KGN could be a novel therapeutic agent targeting AR and/or Smad2 signaling pathways for PC patients at all stages from HSPC to chemo-resistant CRPC.

\section{Conflicts of Interest}

The Authors declare no conflicts of interest associated with this manuscript.

\section{Authors' Contributions}

Conception and design: KM and MI. Performed the experiments: MT and KM. Data analysis and interpretation: KM, KK, YF, TKa, DK, KI, TKo. Manuscript writing: MT, KM and MI. Approval of manuscript: All Authors.

\section{Acknowledgements}

This work was partially supported by Japan Society for the Promotion of Science, KAKENHI Grant Number 21K09340. The Authors are grateful to Ayako Nagasawa for her invaluable contributions to data acquisition.

\section{References}

1 Hussain M, Fizazi K, Saad F, Rathenborg P, Shore N, Ferreira U, Ivashchenko P, Demirhan E, Modelska K, Phung, Krivoshik A and Sternberg CN: Enzalutamide in men with nonmetastatic, castration-resistant prostate cancer. N Engl J Med 378(26): 24652474, 2018. PMID: 29949494. DOI: 10.1056/NEJMoa1800536

2 Smith MR, Saad F, Chowdhury S, Oudard S, Hadaschik BA, Graff JN, Olmos D, Mainwaring PN, Lee JY, Uemura H, LopezGitlitz A, Trudel GC, Espina BM, Shu Y, Park YC, Rackoff WR, 
Yu MK, Small EJ and SPARTAN Investigators: Apalutamide treatment and metastasis-free survival in prostate cancer. $\mathrm{N}$ Engl J Med 378(15): 1408-1418, 2018. PMID: 29420164. DOI: 10.1056/NEJMoa1715546

3 Fizazi K, Shore N, Tammela TL, Ulys A, Vjaters E, Polyakov S, Jievaltas M, Luz M, Alekseev B, Kuss I, Le Berre MA, Petrenciuc O, Snapir A, Sarapohja T, Smith MR and ARAMIS Investigators: Nonmetastatic, castration-resistant prostate cancer and survival with darolutamide. N Engl J Med 383(11): 10401049, 2020. PMID: 32905676. DOI: 10.1056/NEJMoa2001342

4 Schmidt KT, Huitema ADR, Chau CH and Figg WD: Resistance to second-generation androgen receptor antagonists in prostate cancer. Nat Rev Urol 18(4): 209-226, 2021. PMID: 33742189. DOI: $10.1038 / \mathrm{s} 41585-021-00438-4$

5 Paller $\mathrm{C}, \mathrm{Pu} \mathrm{H}$, Begemann DE, Wade CA, Hensley PJ and Kyprianou N: TGF- $\beta$ receptor I inhibitor enhances response to enzalutamide in a pre-clinical model of advanced prostate cancer. Prostate 79(1): 31-43, 2019. PMID: 30155899. DOI: $10.1002 /$ pros. 23708

$6 \mathrm{Li} \mathrm{X}$ and Feng XH: SMAD-oncoprotein interplay: Potential determining factors in targeted therapies. Biochem Pharmacol 180: 114155, 2020. PMID: 32682760. DOI: 10.1016/j.bcp.2020.114155

7 Huang CY, Chung CL, Hu TH, Chen JJ, Liu PF and Chen CL: Recent progress in TGF- $\beta$ inhibitors for cancer therapy. Biomed Pharmacother 134: 111046, 2021. PMID: 33341049. DOI: 10.1016/j.biopha.2020.111046

8 Johnson K, Zhu S, Tremblay MS, Payette JN, Wang J, Bouchez LC, Meeusen S, Althage A, Cho CY, Wu X and Schultz PG: A stem cell-based approach to cartilage repair. Science 336(6082): 717-721, 2012. PMID: 22491093. DOI: 10.1126/science.1215157

9 Wang J, Zhou J, Zhang N, Zhang X and Li Q: A heterocyclic molecule kartogenin induces collagen synthesis of human dermal fibroblasts by activating the smad4/smad5 pathway. Biochem Biophys Res Commun 450(1): 568-574, 2014. PMID: 24928394 DOI: $10.1016 /$ j.bbrc.2014.06.016

10 Cai JY, Zhang L, Chen J and Chen SY: Kartogenin and its application in regenerative medicine. Curr Med Sci 39(1): 1620, 2019. PMID: 30868486. DOI: 10.1007/s11596-019-1994-6

11 Liu T, Li X, Wang T, Chen X, Zhang S, Liao J, Wang W, Zou X and Zhou G: Kartogenin mediates cartilage regeneration by stimulating the IL-6/Stat3-dependent proliferation of cartilage stem/progenitor cells. Biochem Biophys Res Commun 532(3): 385392, 2020. PMID: 32888652. DOI: 10.1016/j.bbrc.2020.08.059

12 Lee AF, Chen MC, Chen CJ, Yang CJ, Huang MS and Liu YP: Reverse epithelial-mesenchymal transition contributes to the regain of drug sensitivity in tyrosine kinase inhibitor-resistant non-small cell lung cancer cells. PLoS One 12(7): e0180383 2017. PMID: 28683123. DOI: 10.1371/journal.pone.0180383

13 Mizutani K, Tomoda M, Ohno Y, Hayashi H, Fujita Y, Kawakami K, Kameyama K, Kato T, Sugiyama T, Itoh Y, Ito M and Deguchi T: Effects of cabazitaxel in renal cell carcinoma cell lines. Anticancer Res 35(12): 6671-6677, 2015. PMID: 26637883
14 Hishida S, Kawakami K, Fujita Y, Kato T, Takai M, Iinuma K, Nakane K, Tsuchiya T, Koie T, Miura Y, Ito M and Mizutani K: Proteomic analysis of extracellular vesicles identified PI3K pathway as a potential therapeutic target for cabazitaxel-resistant prostate cancer. Prostate 81(9): 592-602, 2021. PMID: 33905554. DOI: $10.1002 /$ pros.24138

15 Abida W, Patnaik A, Campbell D, Shapiro J, Bryce AH, McDermott R, Sautois B, Vogelzang NJ, Bambury RM, Voog E, Zhang J, Piulats JM, Ryan CJ, Merseburger AS, Daugaard G, Heidenreich A, Fizazi K, Higano CS, Krieger LE, Sternberg CN, Watkins SP, Despain D, Simmons AD, Loehr A, Dowson M, Golsorkhi T, Chowdhury $\mathrm{S}$ and TRITON2 investigators: Rucaparib in men with metastatic castration-resistant prostate cancer harboring a $B R C A 1$ or $B R C A 2$ gene alteration. J Clin Oncol 38(32): 3763-3772, 2020. PMID: 32795228. DOI: $10.1200 / \mathrm{JCO} .20 .01035$

16 de Bono J, Mateo J, Fizazi K, Saad F, Shore N, Sandhu S, Chi KN, Sartor O, Agarwal N, Olmos D, Thiery-Vuillemin A, Twardowski P, Mehra N, Goessl C, Kang J, Burgents J, Wu W, Kohlmann A, Adelman CA and Hussain M: Olaparib for metastatic castration-resistant prostate cancer. N Engl J Med 382(22): 2091-2102, 2020. PMID: 32343890. DOI: 10.1056/ NEJMoa1911440

17 Song B, Park SH, Zhao JC, Fong KW, Li S, Lee Y, Yang YA, Sridhar S, Lu X, Abdulkadir SA, Vessella RL, Morrissey C, Kuzel TM, Catalona W, Yang X and Yu J: Targeting FOXA1mediated repression of TGF- $\beta$ signaling suppresses castrationresistant prostate cancer progression. J Clin Invest 129(2): 569582, 2019. PMID: 30511964. DOI: 10.1172/JCI122367

18 Schuurmans AL, Bolt J, Veldscholte J and Mulder E: Regulation of growth of $\mathrm{LNCaP}$ human prostate tumor cells by growth factors and steroid hormones. J Steroid Biochem Mol Biol 40(1-3): 193-197, 1991. PMID: 1958520. DOI: 10.1016/0960-0760(91)90182-5

19 Vo BT, Cody B, Cao Y and Khan SA: Differential role of SloanKettering Institute (Ski) protein in Nodal and transforming growth factor-beta (TGF- $\beta$ )-induced Smad signaling in prostate cancer cells. Carcinogenesis 33(11): 2054-2064, 2012. PMID: 22843506. DOI: 10.1093/carcin/bgs 252

20 da Silva HB, Amaral EP, Nolasco EL, de Victo NC, Atique R, Jank CC, Anschau V, Zerbini LF and Correa RG: Dissecting major signaling pathways throughout the development of prostate cancer. Prostate Cancer 2013: 920612, 2013. PMID: 23738079. DOI: $10.1155 / 2013 / 920612$

21 Chipuk JE, Cornelius SC, Pultz NJ, Jorgensen JS, Bonham MJ, Kim SJ and Danielpour D: The androgen receptor represses transforming growth factor-beta signaling through interaction with Smad3. J Biol Chem 277(2): 1240-1248, 2002. PMID: 11707452. DOI: $10.1074 /$ jbc.M108855200

Received July 22, 2021

Revised August 6, 2021

Accepted August 9, 2021 